\title{
Saltwater based fractionation and valorisation of macroalgae
}

\author{
Edward S Jones, ${ }^{a} \oplus$ Sofia Raikova, ${ }^{a}$ Sharif Ebrahim, ${ }^{b}$ Sophie Parsons, ${ }^{c} \odot$ \\ Michael J Allen ${ }^{\mathrm{d}, \mathrm{e}} \odot$ and Christopher J Chuck ${ }^{\mathbf{b}^{*}} \odot$
}

\begin{abstract}
BACKGROUND: Macroalgae are gaining increasing interest as an important biomass feedstock. Yet when valorising marine biomass, the presence of salt can pose a substantial obstacle to the effectiveness of downstream biological and chemical processes, as well as the engineering infrastructure required. Accordingly, dewatering, washing and drying are often considered the first and crucial primary steps in processing marine biomass such macroalgae. The high costs of these processes can make further marine biorefinery commercialisation prohibitive. This investigation assesses simple pre-treatments for macroalgal biomass in saltwater, thereby reducing the freshwater footprint, and removing the need for an energy-intensive washing and drying stage.
\end{abstract}

RESULTS: Using acid and basic catalysts, the carbohydrate and soluble protein components were fractionated into a soluble aqueous phase, for further fermentation and a solid phase suitable for hydrothermal liquefaction. The presence of saltwater was found to aid the fractionation process, solubilising more of the biomass. The use of $\mathrm{H}_{2} \mathrm{SO}_{4}$ produced more monosaccharides, whereas $\mathrm{NaOH}$ solubilised higher levels of biomass at lower temperatures. The aqueous phase was demonstrated to be suitable for biological processing with the salt tolerant yeast Metschnikowia pulcherrima, and the residual solids suitable for processing via hydrothermal liquefaction.

CONCLUSION: By contrast with existing pre-treatment strategies, we demonstrate that an entirely salt-based biochemical conversion route is a potentially viable option. For the first time this work demonstrates that, rather than a hindrance, the presence of saltwater can be advantageous, and could provide an alternative, more cost-effective pathway to achieving a successful macroalgal-based biorefinery.

(c) 2020 Society of Chemical Industry

Supporting information may be found in the online version of this article.

Keywords: bioconversion; biomass; clean processes; algae; fermentation

\section{INTRODUCTION}

Global population growth coupled with a shift towards a lowcarbon economy means that biomass resources are of increasing importance. Macroalgae (seaweed) have been identified as a sustainable biomass resource for the production of food, biofuels, and biochemical building-blocks for the chemical industry. ${ }^{1}$ With higher photosynthetic efficiencies than terrestrial crops, and no freshwater or arable land requirement, macroalgae is an attractive alternative to terrestrial biomass. Although mass cultivation is still a relatively immature technology in Europe $\left(\sim 1500 \mathrm{t} \mathrm{year}^{-1}\right)_{1}^{2}$ the potential is huge with over $30 \mathrm{M} \mathrm{t}$ currently cultivated globally. ${ }^{3}$ Wild harvests have remained steady in recent decades, at c. $1 \mathrm{M}$ t year $^{-1}$ globally. ${ }^{3}$ By contrast to cultivation, European activity accounts for almost a third of this global wild harvest volume. Species with attractive biochemical and/or physiochemical properties have been identified as potential sources of chemicals, particularly in pharmaceuticals where marine polysaccharides such as carrageenan and fucoidan are compounds of interest. ${ }^{4}$

For lower value compounds, macroalgal biomass has been shown to be a suitable source for hydrothermal liquefaction, fermentations and oleaginous yeast production. ${ }^{5}$ However, to exploit macroalgal biomass for lower bulk chemical and fuel production, a number of issues must still be addressed across every part of the supply chain. One of the key issues with the valorisation of macroalgae, which is rarely discussed, is the presence of salt. The presence of salt can pose a substantial obstacle with regards to the effectiveness of downstream biological and chemical processes, as well as with the engineering infrastructure required. Accordingly, expensive dewatering, washing and drying

\footnotetext{
Correspondence to: CJ Chuck, Department of Chemical Engineering, University of Bath, Claverton Down, Bath, BA2 7AY, UK. E-mail: c.chuck@bath.ac.uk

a Centre for Doctoral Training in Sustainable Chemical Technologies, Department of Chemical Engineering, University of Bath, Bath, UK

b Department of Chemical Engineering, University of Bath, Bath, UK

c Department of Mechanical Engineering, University of Bath, Bath, UK

d Plymouth Marine Laboratory, Plymouth, UK

e College of Life and Environmental Sciences, University of Exeter, Exeter, UK
} 
often is considered the first and crucial primary step in processing marine biomasses such as microalgae and macroalgae. These high costs can make further marine biorefinery commercialisation prohibitive. As such, marine biomass research in the most part is carried out with freshwater-washed samples. ${ }^{6}$ Similarly, post-harvest freshwater washing of macroalgae is deemed vital for hydrothermal processing as salt water heated to effective processing temperatures is extremely corrosive and will degrade any steel type rapidly. If processing biologically, most industrially relevant microbes identified for the production of monomers and fuels are not salt-tolerant and cannot grow under such conditions. ${ }^{7}$

Hydrothermal liquefaction ( $\mathrm{HTL}$ ) has shown excellent promise as a conversion technique for the production of fuels and aqueous fertilisers. ${ }^{8}$ However, treatment processes such as HTL are indiscriminate in their hydrolysis of carbohydrate structures, resulting in the complete loss of high-value polysaccharides. Similarly, fermentations are typically only able to use $\leq 50 \%$ of the organic fraction, depending on the saccharide composition and yield. $^{5}$

Fractionation of biomass into individual building block components allows extraction of the high-value products, as well as optimal treatment of the different value fractions for maximum value recovery. Work in the lignocellulosic biorefinery field has demonstrated that the pre-treatment and fractionation of the biomass is of critical importance to direct mass flow between processing steps, to optimally valorise the biomass, and to employ the most suitable downstream process for the fraction. ${ }^{9}$ The distribution of fermentable material into a readily assessable aqueous phase is a key priority, whereas left-over solids can be processed thermochemically. Such a method has additional benefits: the presence of common heteroatoms [e.g. nitrogen (N) and sulfur (S)] in the whole biomass can lead to undesirable $\mathrm{NO}_{\mathrm{x}}$ and $\mathrm{SO}_{\mathrm{x}}$ emissions when combusting the biofuel products, as well as difficulties in processing and handling of biocrudes. ${ }^{10,11}$ However, the presence of $\mathrm{N}$ - or S-containing compounds in the aqueous or solid residues produced by thermochemical processing may be desired, with both the aqueous phase and solids being identified as potential fertilizer products for soil amelioration. ${ }^{10,12}$ Previously, biomass pre-treatment techniques to reduce $\mathrm{N}$ content in the resulting bio-crude from HTL have been successfully demonstrated, albeit at the expense of requiring an additional aqueous processing step. $^{10}$

Fractionation techniques for the separation of lignin, cellulose and hemicellulose, are well-demonstrated in the literature for lignocellulosic biomass, but the fractionation of macroalgal species is not. Macroalgae typically comprise cellulose, polysaccharide carbohydrates, and a small quantity of lipids and proteins, ${ }^{13}$ so should be amenable to similar processing techniques to those applied to lignocellulosic biomass. Typical treatments applied to macroalgae include dilute acid or base treatment, mixed aqueous/organic solvent washings, or use of chelating salt solutions to either dissolve carbohydrates in solution or to enhance the properties of the residual solids fraction by selective stripping of components (e.g. agar or alginate). ${ }^{14-19}$ The presence of salt in raw seaweed biomass, however, provides uncertainty as to the effectiveness and efficacy of processing, and the only previous work in this area has evaluated the effect of both residual marine salts and inorganic catalytic salts on the HTL process, rather than investigating the role of salt water in the fractionation process. $^{20-23}$ Literature reports typically tend to favour dilute acid treatment as the preferred chemical treatment of algal biomass to produce hydrolysates. ${ }^{22,24-26}$ Primarily, this is due to the desirable mechanism of acid hydrolysis on structural polysaccharides: cleavage of the linkage between individual monosaccharide units under acidic conditions results in a high sugar concentration. ${ }^{17}$ However, typical acid hydrolysis conditions are harsh (1-10\% acid $\mathrm{w} / \mathrm{v}, 120-200^{\circ} \mathrm{C}$ ), and could be problematic for the design of industrial-scale reactors, a key concern being the risk of material corrosion. ${ }^{17}$ Acid hydrolysis also is associated with the risk of producing toxic inhibitors, for example the degradation of hexose sugars (i.e. glucose), producing 5-(hydroxymethyl)furfural (5-HMF). ${ }^{27}$ However, some studies have reported lower production of inhibitory side-products when treating lignocellulosic biomass with inorganic salts during hydrolysis/saccharification pretreatments. $^{28}$

Microbial fermentation is a platform unit operation in both conceptual biorefineries, and many existing industrial biorefinery processes. Typically, a combination of pre-treatment and hydrolysis techniques are employed to produce a broth of fermentable sugars. ${ }^{29} \mathrm{~A}$ multi-step process often is required to ensure complete the hydrolysis of poly- and oligo-saccharides, becuase many industrially suitable microbes are not able to fully metabolise the various complex oligosaccharides resulting from one-step hydrolysis reactions of untreated biomass. ${ }^{30-33}$ Additionally, detoxification steps often are required to remove or neutralise inhibitory compounds that are produced as co-products of the hydrolysis reactions. ${ }^{34,35}$ However, recent work has demonstrated that the yeast Metschnikowia pulcherrima is able to metabolise both complex water soluble oligosaccharides, and mono-/di-saccharides sourced from varied biomass sources (agricultural, aquatic and industrial), as well as exhibiting high tolerance to inhibitors typically found in lignocellulosic hydrolysates. ${ }^{36-38}$ Additionally, $M$. pulcherrima is found to produce a number of desirable products, such as 2-phenylethanol, and high-value lipids. ${ }^{37}$ Previous studies have shown that optimal $M$. pulcherrima cultures have elevated levels of $\mathrm{NaCl}\left(\leq 6 \mathrm{~g} \mathrm{~L}^{-1}\right)$; however, the salt tolerance of $M$. pulcherrima at marine salinities (c. $35 \mathrm{~g} \mathrm{~L}^{-1} \mathrm{NaCl}$ ) has not been reported on. ${ }^{39}$

Given the gap in literature relating to salt water fractionation, this study aims to evaluate simple macroalgal fractionation reactions in model seawater and assess the impact of salt on typical downstream processes, in this instance, HTL of residual solids and fermentation of the aqueous hydrolysate.

\section{MATERIALS AND METHODS}

\section{Model seawater}

A single 10-L batch of seawater was prepared for use in all experiments by dissolving Aquarium Systems Reef Crystals salt (Sarrebourg, France) in deionised (DI) water $\left(\sim 40 \mathrm{~g} \mathrm{~L}^{-1}\right)$. Temperaturecorrected specific gravity was checked and adjusted to 1.025 (equivalent to 35 ppt seawater) using a D\&D $\mathrm{H}_{2}$ Ocean brand hand-held salinity refractometer. A single batch of brine (70 ppt) was made up by dissolving salt in DI water at approx. $80 \mathrm{~g} \mathrm{~L}^{-1}$. Brackish water (10 ppt salt) was made up by mixing at an approximate 3:7 volume ratio of seawater (35 ppt) and DI water (0 ppt), and confirming with specific gravity measurement of 1.007 to 1.008 .

\section{Macroalgae}

Samples of the macroalgae Fucus serratus (FS) were wildharvested from Broadsands Beach, Paignton $\left(50^{\circ} 24^{\prime} 24.9^{\prime \prime} \mathrm{N}, 3^{\circ}\right.$ $33^{\prime} 16.2^{\prime \prime} \mathrm{W}$ ) between November 2017 and January 2018. Samples were frozen at $-80{ }^{\circ} \mathrm{C}$ and then freeze-dried at $-55^{\circ} \mathrm{C}$ 
(Coolsafe, Scanvac) and then triturated to a fine powder, sieved to $<1.4 \mathrm{~mm}$, and stored in sealed containers at $-80{ }^{\circ} \mathrm{C}$ to prevent degradation.

\section{Acid/base catalyst solutions}

An $11 \mathrm{~mol} \mathrm{~L}^{-1}$ sodium hydroxide $(\mathrm{NaOH})$ stock solution was prepared by dissolving Fisher BioReagent brand $\geq 98 \% \mathrm{NaOH}$ pellets in DI water at $452 \mathrm{~g} \mathrm{~L}^{-1}$. A $1.8 \mathrm{~mol} \mathrm{~L}^{-1}$ sulfuric acid stock solution was prepared by making $5.0 \mathrm{~mL}$ conc. $\mathrm{H}_{2} \mathrm{SO}_{4}$ (99.99\%) (Sigma Aldrich brand) up to $50 \mathrm{~mL}$ with DI water in a volumetric flask. For the acid/base concentration screening experiment [Fig. 1 (a) and (b)], a double-strength concentrate was made up to maintain the same total reaction volume.

\section{Small-scale hydrolysis reaction}

ACE pressure tubes $(15 \mathrm{~mL})$ were used as reaction vessels, with constant agitation provided by a $10 \times 5 \mathrm{~mm}$ crossbar magnetic stirrer. Biomass loading rates of $5 \mathrm{wt} \%$ FS were used to ensure optimal stirring. ${ }^{10}$

Temperature control was achieved by placing an insulated aluminium block heat sink on a stirrer hotplate, with machined recesses to snugly accept the $15-\mathrm{mL}$ ACE pressure tubes ( $25.4 \mathrm{~mm}$ outside diameter). The aluminium block was pre-heated to the target reaction temperature, allowing a period of $\geq 20 \mathrm{~min}$ for the block temperature to stabilise once the thermal set-point was achieved. Temperature control was achieved by way of an IKA ETS-D5 electronic contact thermometer inserted into a drilled thermowell in the centre of the reaction block.
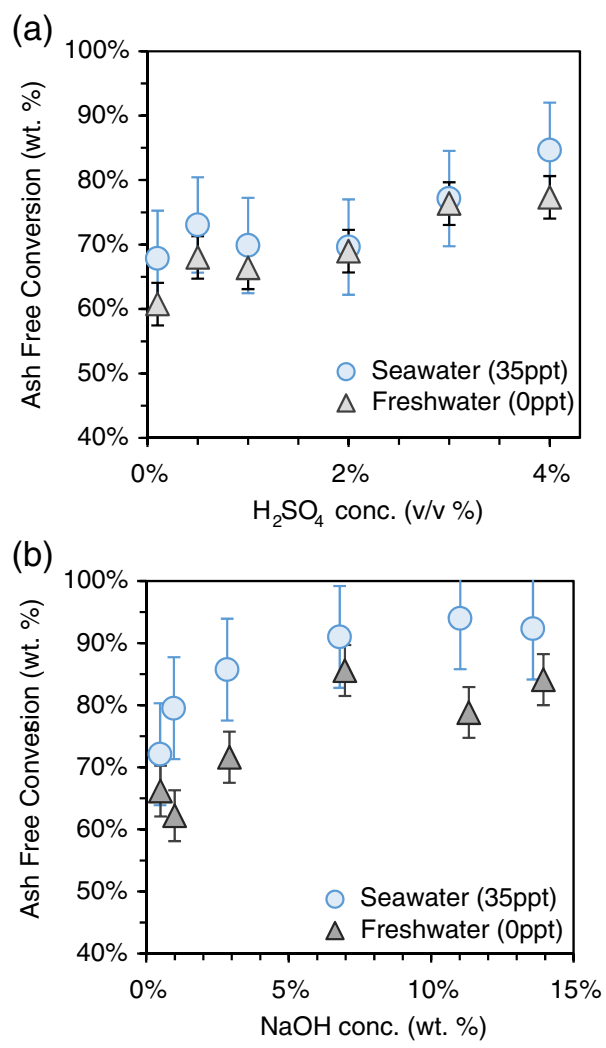

Figure 1. Conversion yields for Fucus serratus processed in freshwater (0 ppt salt) and saltwater ( $35 \mathrm{ppt}$ ), at reaction temperature $87.5^{\circ} \mathrm{C}$, total reaction time 20 min, and using (a) a $\mathrm{H}_{2} \mathrm{SO}_{4}$ catalyst; (b) a $\mathrm{NaOH}$ catalyst. Error bars show 1 SD determined with repeats in the later multifactorial screening dataset.
Solvent of varying salinity (freshwater, brackish water, seawater or brine) was mixed with aqueous catalyst solution $(\mathrm{NaOH}$ or $\mathrm{H}_{2} \mathrm{SO}_{4}$ ) at a volume ratio of $10: 2$ to give a total of $12 \mathrm{~mL}$ working volume in the pressure tube, to which $0.51 \mathrm{~g}$ FS biomass was added, along with a $10 \times 5 \mathrm{~mm}$ crossbar magnetic stirrer. The pressure tube was then quickly sealed, placed into the pre-heated reaction block on the stirrer-hotplate, and continuously stirred by the magnetic crossbar for $20 \mathrm{~min}$. Once the reaction time had elapsed, the pressure tubes were removed from the heated reaction block and placed into a roomtemperature aluminium block to rapidly quench the temperature. The contents of the reaction tube were transferred to a pre-tared 50-mL Falcon centrifuge tube and adjusted to $\mathrm{pH}$ 5-6 using $\mathrm{HCl} / \mathrm{NaOH}$.

An initial catalyst strength screening experiment was performed. Stock solutions of $\mathrm{NaOH}$ and $\mathrm{H}_{2} \mathrm{SO}_{4}$ were prepared, using the literature convention of wt $\%$ for $\mathrm{NaOH}$ and a v/v\% for $\mathrm{H}_{2} \mathrm{SO}_{4}$ to allow direct comparison across the literature. ${ }^{10}$ Such that a $2 \mathrm{~mL}$ addition of $\mathrm{NaOH}$ solution to $10 \mathrm{~mL}$ of water resulted in $0.5,1.0,2.8,6.8,11.0$ and $13.6 \mathrm{wt} \%$ active $\mathrm{NaOH}$ in the final $12-\mathrm{mL}$ reaction volume. Similarly, stock solutions of $\mathrm{H}_{2} \mathrm{SO}_{4}$ were prepared such that $2 \mathrm{~mL}$ volume addition of the stock solution resulted in $0.1,0.5,1.0,2.0,3.0$ and $4.0 \mathrm{v} / \mathrm{v} \% \mathrm{H}_{2} \mathrm{SO}_{4}$ in the total reaction mixture. Catalyst strength screening was carried out at $87.5^{\circ} \mathrm{C}$, in both fresh ( $\left.0 \mathrm{ppt}\right)$ and salt (35 ppt) water.

Influence of reaction temperature, salinity and choice of catalyst on the hydrolysis yield was investigated by use of a multifactorial screening study. Experimental design was conducted in the software package MODDE PRO (v12.1), with continuous independent factors of reaction temperature $\left(25-150^{\circ} \mathrm{C}\right)$, and salinity $(0-70 \mathrm{ppt}$, freshwater to heavy brine), and categorical factors of choice of catalyst (acid, base, none); catalyst strength was kept constant. A full summary of reaction solvent volumes, catalyst concentrations and temperatures is provided in the Supporting Information, Table S1.

\section{Yield calculation}

The conversion yields of biomass solids were determined for the hydrolysis reaction. The reaction solution was centrifuged, and the supernatant aspirated into a $30-\mathrm{mL}$ glass sample vial. The resultant solid was resuspended in $6 \mathrm{~mL}$ DI water with the use of a benchtop vortex mixer and centrifuged again. Supernatant from the washing was transferred to the $30-\mathrm{mL}$ glass vial along with the primary aqueous fraction. The centrifuge tube with the wet pellets of solids was then placed in a laboratory oven (Plus II Oven, Gallenkamp) at $60{ }^{\circ} \mathrm{C}$ until constant weight was achieved.

Conversion yield (\%) was calculated as follows:

$$
\text { Yield }_{\text {conversion }}=\frac{\left(m_{\text {starting FS }}-m_{\text {oven dry pellet }}\right)}{m_{\text {starting FS }}} \times 100 \%
$$

where $m$ is the mass $(\mathrm{g})$ of starting $F S$, and the oven dried pellet. Ash-free conversion yield (\%) was calculated later using the ash content (\%) determined by TGA as follows:

Yield $_{\text {Ash-free }}=\frac{\left(m_{\text {starting FS }}-\left[m_{\text {oven dry pellet }} \times(100 \%-a s h \%)\right]\right)}{m_{\text {starting FS }}} \times 100 \%$

Where $a s h \%$ is the ash content of solids as determined by TGA, full method for which is explained later. 


\section{Media preparation for fermentation}

A pre-inoculum broth was prepared by inoculating $10 \mathrm{~mL}$ soymalt broth (SMB: soy peptone $30 \mathrm{~g} \mathrm{~L}^{-1}$; malt extract $25 \mathrm{~g} \mathrm{~L}^{-1}$; $\mathrm{pH} 5$; in DI water) with a single colony of M. pulcherrima NCYC 4331 (National Collection of Yeast Cultures, Norfolk, UK), from an agar plate (YMD: yeast extract $10 \mathrm{~g} \mathrm{~L}^{-1}$, malt extract $20 \mathrm{~g} \mathrm{~L}^{-1}$, glucose $20 \mathrm{~g} \mathrm{~L}^{-1}$, agar $15 \mathrm{~g} \mathrm{~L}^{-1}, \mathrm{pH} 5$ in DI water). The inoculum was prepared in a 100-mL unbaffled Erlenmeyer (shake) flask, incubated for $24 \mathrm{~h}$ at $20^{\circ} \mathrm{C}$ in temperature-controlled cabinets, at a $10 \%(\mathrm{v} / \mathrm{v})$ working volume, and agitated on orbital shakers (Unimax 2010, Heidolph) at $180 \mathrm{rpm}^{5}$

\section{6-well plate fermentation}

Fermentability was assessed using 96-well plates. Plates (Greiner BioOne Cellstar, suspension culture plate, F-Bottom with lid) were prepared as follows: $7.5 \mu \mathrm{L}$ tetracycline/gentamicin stock solution (960 $\mathrm{mg} \mathrm{L}^{-1}$ tetracycline; $1200 \mathrm{mg} \mathrm{L}^{-1}$ gentamicin) was combined with $285 \mu \mathrm{L}$ macroalgae hydrolysate, and inoculated with $7.5 \mu \mathrm{L}(2.5 \% \mathrm{v} / \mathrm{v})$ inoculum (giving a final working volume of $300 \mu \mathrm{L}$ per well, containing $12 \mathrm{mg} \mathrm{L}^{-1}$ tetracycline and $15 \mathrm{mg} \mathrm{L}^{-1}$ gentamicin). Plates were covered loosely with a plate lid, incubated at $25^{\circ} \mathrm{C}$ at $200 \mathrm{rpm}$ idle continuous shaking frequency (BMG Labtech, CLARIOstar Plus) for 132 h (5.5 days), with light absorbance at $600 \mathrm{~nm}$ wavelength $\left(\mathrm{OD}_{600}\right)$ analysed every $30 \mathrm{~min}$, following $300 \mathrm{~s}$ of $200 \mathrm{rpm}$ double orbital shaking to ensure sample homogeneity. The initial reading of $\mathrm{OD}_{600}$ for each well was subtracted from the subsequent and final $O_{600}$ readings.

\section{Large-scale hydrolysis reaction}

In a stirred and jacketed reactor with a 5-L working volume (Parr Instrument Company), seawater (574.9 $\mathrm{mL})$, freshwater $(1804.0 \mathrm{~mL})$ and catalyst solution $(276.5 \mathrm{~mL} 11 \mathrm{M} \mathrm{NaOH})$ were added to make a total reaction volume of $2655 \mathrm{~mL}$ brackish water at $4.3 \mathrm{wt} \% \mathrm{NaOH}$. This mixture was brought to reaction temperature $\left(90^{\circ} \mathrm{C}\right)$ under vigorous stirring (500 rpm stirrer speed), and temperature maintained by PID control. On reaching reaction temperature, the solid macroalgae was added (450 g, equivalent to $\sim 13.5$ wt\%), and the reaction stopwatch started. Samples $(\approx 100 \mathrm{~mL}$ each) were extracted from the vessel using a $1 / 2 "$ sampling ball-valve fitted at the base of the reactor, collected at 5 -min intervals starting at $t=20 \mathrm{~min}$ until $t=90 \mathrm{~min}$. Full summarised details of the reaction charge are detailed in Table S2.

\section{Large-scale hydrolysate clarification and work-up}

Samples drawn from the Parr 5- $L$ reactor were transferred to 250-mL wide-mouth HDPE centrifuge bottles (Nalgene), and centrifuged for $30 \mathrm{~min}(\mathrm{RCF}=2990)$. Supernatant was transferred to fresh tared centrifuge tubes ( $50 \mathrm{~mL}$ conical base, Falcon), and $\mathrm{pH}$-adjusted to $<5.0$ using $10 \mathrm{~mol} \mathrm{~L}^{-1}$ and $1 \mathrm{~mol} \mathrm{~L}^{-1} \mathrm{HCl}$ to minimise the total volume of $\mathrm{HCl}$ added. Primary solids in the 250-mL centrifuge bottles were set aside for processing later.

The $\mathrm{pH}<5.0$ adjustment of the primary supernatant caused significant precipitation of solids; hence, solutions were centrifuged for a further $30 \mathrm{~min}(\mathrm{RCF}=2990)$. Secondary supernatant again was transferred to a fresh tared centrifuge tube, and $\mathrm{pH}$-adjusted to $>10.1$ using powdered $\mathrm{Ca}(\mathrm{OH})_{2}$ (calcium hydroxide, $98 \%$, extra pure, ACROS Organics ${ }^{\mathrm{TM}}$ ). The addition of $\mathrm{Ca}(\mathrm{OH})_{2}$ caused further precipitation; the secondary supernatant was returned to the centrifuge for a further $30 \mathrm{~min}(\mathrm{RCF}=2990)$ to isolate the secondary solids. Secondary solids were retained.
The tertiary supernatant was a clear straw-coloured liquid, and did not require any further clarification. The $\mathrm{pH}$ was adjusted to $\mathrm{pH} 5$ with $\mathrm{HCl}$, the clarified $\mathrm{pH} 5$ hydrolysate was transferred to $100-\mathrm{mL}$ shake flasks (Erlenmeyer flask), and autoclaved at $121^{\circ} \mathrm{C}$ in preparation for inoculation with $M$. pulcherrima inoculum solution.

\section{Shake flask cultivation}

Autoclaved hydrolysate was prepared in $100-\mathrm{mL}$ shake flasks as described in the previous section, and a solution of inoculum was prepared as described previously under 'Media preparation for fermentation': $1 \mathrm{~mL}$ of hydrolysate was taken and set aside for use as a blank for the $\mathrm{OD}_{600}$ measurement. The M. pulcherrima inoculum was prepared such that the $\mathrm{OD}_{600}$ of the fermentation broth would be equal to 0.5 immediately after inoculation. To determine the required volume of inoculum for each shake flask the following equation was used:

$$
V_{\text {inoculum required }}=\frac{0.5 \times V_{\text {hydrolysate in flask }}}{\mathrm{OD}_{600_{\text {inoculum }}}}
$$

where $V$ is volume $(\mathrm{mL})$.

The $\mathrm{OD}_{600}$ of the inoculum was assessed against a blank of DI water, and the volume of hydrolysate in the shake flask assessed from the level gradients on the side. Inoculated shake-flasks were incubated at $20^{\circ} \mathrm{C}$ in temperature-controlled cabinets, and agitated on orbital shakers (Unimax 2010, Heidolph) at $180 \mathrm{rpm}$. One millilitre samples of the fermentation broth were extracted daily for 6 days $\left(144 \mathrm{~h}\right.$ ), and analysed for $\mathrm{OD}_{600}$ against the blank of pre-inoculated hydrolysate collected previously. Between measurements, the blank was frozen, and when defrosted was homogenized on a bench-top vortex mixer before measurement.

Determination of dry cell weight (DCW) was completed as described by Abeln et al. ${ }^{5}$ Samples of the culture were centrifuged, the supernatant was aspirated using a micropipette and set aside, the pellet was re-suspended in DI water, centrifuged again, and the wash-water supernatant discarded. Washes with DI water were repeated until the supernatant was clear in colour. The subsequent water-wet pellet was frozen $\left(-20^{\circ} \mathrm{C}\right)$, lyophilised and DCW gravimetrically assessed.

\section{Hydrothermal liquefaction (HTL)}

Primary solids from the 5-L scale fermentation work-up were resuspended in equal volume of $\mathrm{DI}$ water, neutralised to $\mathrm{pH} 5$ to 7 with $1 \mathrm{~mol} \mathrm{~L}^{-1} \mathrm{HCl}$, and centrifuged for $10 \mathrm{~min}$. Supernatant washings were discarded, and the washed solids were dried in a laboratory oven (Plus II Oven, Gallenkamp) at $60^{\circ} \mathrm{C}$ until constant weight was achieved.

The HTL was performed on the solids as described by Raikova et $a .^{8}$ Batch reactors were fabricated using stainless steel tubing, with Swagelok ${ }^{\circledast}$ fittings as described ibid. The tubular reactor was loaded with $1.5 \mathrm{~g}$ oven-dried primary solids and $13.5 \mathrm{~mL}$ DI water, and heated within a vertical tubular furnace until the reaction temperature of $350^{\circ} \mathrm{C}$ was reached, then removed from the furnace and allowed to cool to room temperature.

After cooling, gaseous products were released via the needle valve into an inverted, water-filled measuring cylinder to measure gaseous fraction volume. Gas phase yields are calculated using the ideal gas law, and approximating the gas phase as $100 \%$ $\mathrm{CO}_{2}$, with $44 \mathrm{~g} \mathrm{~mol}^{-1}$ molecular weight and $22.465 \mathrm{dm}^{3} \mathrm{~mol}^{-1} \mathrm{i}-$ deal volume, as demonstrated previously by Raikova et al. $8,11,40$ The yield of gaseous product was determined with the following: 


$$
\text { yield }_{\text {gas }}=\frac{\left(V_{\text {gas }} \times 1.789 \times 10^{-3}\right)}{m_{\text {dry biomass }}} \times 100 \%
$$

Following this, the aqueous phase was decanted from the reactor contents and filtered through a Fisher qualitative filter paper pre-dried overnight at $60^{\circ} \mathrm{C}$. The product yield in the water phase was determined by leaving a $2.5 \mathrm{~g}$ aliquot of the aqueous phase to dry in a $60^{\circ} \mathrm{C}$ oven overnight and scaling the residue yield to the total aqueous phase mass. Aqueous phase residue yield was determined using the following ${ }^{8}$ :

$$
\text { yield }_{\text {aqueous residue }}=\frac{m_{\text {residue }}}{m_{\text {dry biomass }}} \times 100 \%
$$

The remaining biocrude and char phase was washed from the reactor using chloroform until the solvent ran clear, and filtered through the same filter paper used to separate the aqueous phase (after drying with an air stream to ensure evaporation of residual water). The filter paper and collected char were washed thoroughly with chloroform to remove all remaining biocrude. The filtrate was collected, and solvent removed under vacuum $\left(40^{\circ} \mathrm{C}\right.$, $72 \mathrm{mBar}$ ) until no further solvent evaporation was observed visually. Biocrude samples were transferred to $30-\mathrm{mL}$ vials using a small volume of chloroform; solvent was removed in vacuo, and vials were left to vent to atmosphere via a needle for a further $12 \mathrm{~h}$ to remove residual solvent. Biocrude yield was determined using the following equation ${ }^{8}$ :

$$
\text { yield }_{\text {biocrude }}=\frac{m_{\text {biocrude }}}{m_{\text {dry biomass }}} \times 100 \%
$$

The solids char yield was calculated from the mass of the retentate collected on the filter paper after drying overnight in an oven at $60^{\circ} \mathrm{C}$. Solid yield was determined as follows ${ }^{8}$ :

$$
\text { yield }_{\text {solids }}=\frac{m_{\text {solid }}}{m_{\text {dry biomass }}} \times 100 \%
$$

\section{Characterisation}

Thermogravimetric analysis (TGA) was performed on a Setaram Setsys Evolution TGA 16/18. The Calisto programme was used to collect and process data. Samples were loaded individually into a $170-\mu \mathrm{L}$ alumina crucible. Under an argon atmosphere, samples were held at room temperature for $20 \mathrm{~min}$, with temperature ramped to $800^{\circ} \mathrm{C}$ over $20 \mathrm{~min}$, and held at $800^{\circ} \mathrm{C}$ under argon for $30 \mathrm{~min}$. The atmosphere was then swapped to air whilst maintaining a temperature of $800^{\circ} \mathrm{C}$ for $40 \mathrm{~min}$, followed by cooling to ambient temperature over $20 \mathrm{~min}$. Ash content was determined by taking the final mass at the end of the 40 min under air, and expressing this as $\%$ of the starting mass.

$$
\text { Ash } \%=\frac{m_{800^{\circ} \mathrm{C} \text { residue }}}{m_{\text {starting }}} \times 100 \%
$$

Liquid chromatography mass spectrometry (LC-MS) analysis was performed using a Dionex UltiMate 3000 LC system (Thermo Scientific). The LC method was performed as published by Sluiter et $a l .{ }^{41}$ A BioRad Aminex HPX-87H column was used, with a $50-\mu \mathrm{L}$ injection volume, a mobile phase of $5 \mathrm{mmol} \mathrm{L}^{-1}$

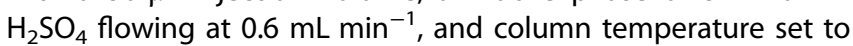

$60^{\circ} \mathrm{C}$. Detection was made by quadrupole time-of-flight (QTOF) MS, using a Bruker MaXis HD II spectrometer, with the ESI in negative ion mode.

Samples were prepared for LC by centrifuging in 1.5-mL Eppendorf tubes at $13500 \mathrm{rpm}$ for $10 \mathrm{~min}$, then passing through a $0.22-\mu \mathrm{m}$ PTFE membrane syringe filter. The clarified hydrolysate then was diluted 1:10 with $0.22-\mu \mathrm{m}$-filtered DI water.

Elemental analysis (CHN) of solids was carried out externally by OEA Laboratories Limited (Callington, UK). Elemental analysis was carried out in duplicate for each sample, and the average value reported.

Total organic carbon (TOC) and total nitrogen (TN) analysis of aqueous samples were carried out with an automated TOC-L analyser (Shimadzu) fitted with a TNM-L total nitrogen analyser unit and an ASI-L autosampler. Analysis was carried out in triplicate and average values reported.

The $\mathrm{OD}_{600}$ of the fermentation broth was assessed in a spectrophotometer (Spectronic 200, ThermoFisher Scientific), using 4.5-mL disposable polystyrene cuvettes (Fisherbrand ${ }^{\mathrm{TM}}$ ), against a blank of pre-inoculated hydrolysate collected before inoculation and frozen between measurements (unless otherwise stated). Samples of fermentation broth were diluted with DI water to an $\mathrm{OD}_{600}$ in the range 0 to 1 , and the final $\mathrm{OD}_{600}$ reported was equal to:

$$
\mathrm{OD}_{600 \text { reported }}=\mathrm{OD}_{600 \text { instrument }} \times[\text { dilution factor }]
$$

Samples that had been frozen prior to measurement were defrosted quickly in a water bath, and vortexed on a benchtop vortex mixer to homogenise before measurement.

\section{RESULTS AND DISCUSSION Effect of hydrolysis reaction conditions}

Hydrolysis of $F S$ biomass was carried out at $87.5^{\circ} \mathrm{C}$, under acidic and basic conditions, in either fresh- or saltwater. The conversion of biomass to soluble products is presented in Fig. 1.

For both acid and base catalysts, conversion yield tends to increase with catalyst concentration, although a plateau is observed above $7.0 \mathrm{wt} \% \mathrm{NaOH}$ for both fresh- and saltwater conditions [Fig. 1(b)], beyond which no improvement in conversion is seen. Hydrolysis performance in saltwater is similar to that in freshwater for acid catalysis, but saltwater was found to enhance the efficiency of conversion for the $\mathrm{NaOH}$ catalyst substantially relative to freshwater.

Figure 1 confirms that the catalyst strengths used by Hu et al. of $2.0 \mathrm{v} / \mathrm{v} \% \mathrm{H}_{2} \mathrm{SO}_{4}$ and $7.0 \mathrm{wt} \% \mathrm{NaOH}$ in their microalgae study, were appropriate for this study in macroalgae. ${ }^{10}$ Catalyst loadings of $2.0 \mathrm{v} / \mathrm{v} \% \mathrm{H}_{2} \mathrm{SO}_{4}$ and $7.0 \mathrm{wt} \% \mathrm{NaOH}$ therefore were selected for the multifactorial screening study of temperature, salinity and catalyst choice. Ash-free yields are summarised in Fig. 2.

The average ash-free conversion yields ranged between $43.0 \%$ and $93.9 \%$, depending on the conditions selected. Temperature was observed to have a strong effect on the overall ash-free hydrolysis yield, with higher temperature resulting in higher conversion yields. At low and mid-salinity values, base-catalysed conditions tended to give the best conversions, although uncatalysed became more effective at extremely high salinity (heavy brine solutions with salt concentrations of $70 \mathrm{ppt}$ ).

The CHN composition of the solid residues, and TOC / TN of the aqueous hydrolysates were carried out individually (Tables S3 and 


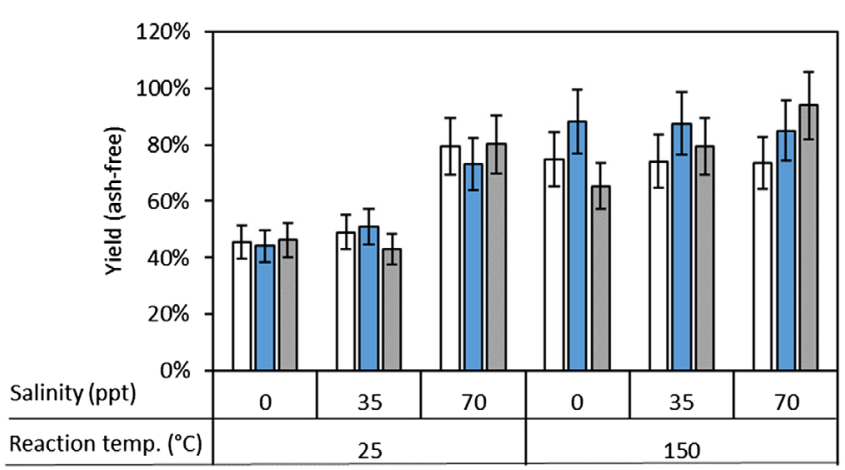

$\square$ Acid $\square$ Base $\square$ None

Figure 2. Effect of temperature, salinity and catalyst type on conversion yields from hydrolysis of $F$. serratus. Hydrolysis experiments carried out under acid $\left(2 \mathrm{v} / \mathrm{v} \% \mathrm{H}_{2} \mathrm{SO}_{4}\right)$, base $(7.0 \mathrm{wt} \% \mathrm{NaOH})$,or uncatalyzed conditions, at temperatures of 25 and $150^{\circ} \mathrm{C}$, and salinities of 0,35 and $70 \mathrm{ppt}$. All reactions carried out for $20 \mathrm{~min}$. Error bars set at the SE observed in this experiment. Colour version available online.

S4). Carbon (C) content of the residual solids ranged between $37.32 \%$ and $54.85 \%, \mathrm{H}$ content ranged between $5.11 \%$ and $8.96 \%$, and $\mathrm{N}$ ranged between $0.91 \%$ and $2.79 \%$. Comparisons between variables were made with a two-sample unequal variance Student's $t$-test.

Temperature was observed to have a strong influence on the $C$ content of the residual solids, with higher temperature resulting in higher $\mathrm{C}$ content for all catalysts and salinities (an average of $40.32 \%$ at low temp versus $46.73 \%$ at high temp; $P=0.004$ ); however, no similar global temperature correlation was observed for $\mathrm{H}$ or $\mathrm{N}$ content. Catalyst choice showed no significant influence on $\mathrm{C}$ content in the solids, however, base treatment at high temperature produced solids with a higher $\mathrm{H}$ content than acid treatment (average of $5.45 \%$ under high-temp acid treatment versus $7.97 \%$ under high-temp base treatment; $P=0.040$ ), and base treatment in both low and high temperature resulted in lower $\mathrm{N}$ content in the solids compared to both acid and uncatalysed hydrolysis reactions [average low-temp acid $\mathrm{N}$ content $1.93 \%$ versus low-temp base treatment $1.48 \%(P=0.018)$ and high-temp acid $\mathrm{N}$ content of $2.28 \%$ versus high-temp base $\mathrm{N}$ content $0.94 \%(P=0.008)$ for low and high temperatures, respectively].

The TOC and TN concentrations in the aqueous hydrolysate followed a similar pattern, with TOC ranging between 2875 and $11063 \mathrm{mg} \mathrm{L}^{-1}$, and $\mathrm{TN}$ ranging between 136 and $609 \mathrm{mg} \mathrm{L}^{-1}$. Higher temperature reactions consistently resulted in higher concentrations of both TOC and TN compared to the lower temperature for all catalyst and salinities. Catalyst choice, unlike the $C$ content of residual solids, had a large influence on the TOC in the hydrolysate, with base treatment resulting in higher TOC in the hydrolysate for all temperatures and salinities. Again, the influence of base treatment on the $\mathrm{N}$ was significant, with base treatment resulting in higher TN in the hydrolysate compared to both acid and uncatalysed treatments, and all temperatures and salinities.

The C:N ratio was used as a proxy for the effect of experimental conditions on the carbohydrate/protein fractionation. Higher C:N ratio in a particular phase suggests a relative concentration of carbonaceous compounds (e.g. carbohydrate residues) compared to $\mathrm{N}$, conversely a lower $\mathrm{C}: \mathrm{N}$ ratio in a phase suggests a relative higher concentration of nitrogenated compounds (e.g. protein residues). High C:N ratio is desired in the solids, as this indicates a lower concentration of heteroatoms (e.g. N, S, O) and a likely better quality HTL bio-crude product. Conversely a low TOC:TN ratio is desired in the hydrolysate, because this indicates a higher concentration of nitrogenated compounds in the aqueous phase, which could be beneficial for the use of the aqueous phase as a fertiliser.

Main effects plots of C:N ratio in the solids, and TOC:TN in the hydrolysate were produced in MINITAB v.18.1 (Fig. S1) which show that for high C:N in the solids, and low TOC:TN in the aqueous phase, base treatment has the strongest single effect, followed by high temperature. Focusing just on main effects, however, can miss some important interaction details, for example if the presence of salt influenced the action of the base treatment. To investigate the interaction effects of temperature, salinity and catalyst choice on the relative $C$ and nitroNgen partition in the residual solids and hydrolysate, main effects plots and interaction plots were produced in MINITAB v18.1 (Fig. 3).

Figure 3(a) shows the interaction plots of the three experimental variables on the $\mathrm{C}: \mathrm{N}$ wt\% ratio in the residual solids. Parallel lines on an interaction plot suggest no interaction between the plotted variables; however, diverging, converging or crossing lines indicate an interaction between the two plotted factors. The interaction of catalyst choice and salinity [Fig. 3(a)-i] shows that the highest C:N ratios were achieved at lower salinities, and vice versa. The relatively parallel lines in the interaction plot for salinity and temperature [Fig. 3(a)-ii] show that there is not any particularly strong interaction between these two factors; however, the increased spacing at high temperature does suggest that any salinity specific effects (higher C:N ratio at low salinities) are enhanced at higher temperature. The interaction effect of temperature and catalysts [Fig. 3(a)-iii] again showed a strong interaction, with the combination of high temperature and base having the strongest effect on C:N ratio enhancement; however, littleto-no effect for the acid-catalysed hydrolysis, and a slight decrease in the $\mathrm{C}: \mathrm{N}$ ratio with increasing temperature for uncatalysed reactions. Figure 3(b) shows the interaction plots of the three experimental variables on the TOC:TN ratio in the aqueous hydrolysate. The gapping between points on the cross-interaction plot of salinity and catalyst choice [Fig. 3(b)-i] shows that the specific impact of salinity on the TOC:TN [from Fig. S1(b), lower salinity tends to result in higher TOC:TN, whereas higher salinity tends to result in lower TOC:TN] is less pronounced under basecatalysed conditions. The cross-interaction plot of catalyst choice and temperature [Fig. 3(b)-iii] on the TOC:TN ratio shows that under acid- and base-treated reactions the effect of temperature is to decrease the TOC:TN ratio in the hydrolysate; however, under uncatalysed conditions the effect of higher temperature is to increase TOC:TN in the hydrolysate - in the absence of a catalyst to assist in protein depolymerisation, increasing temperatures enhance the dissolution of easily accessible carbohydrates, effectively concentrating the nitrogen in the solid phase.

A multivariate partial least squares (PLS) model of temperature versus salinity versus catalyst was subsequently developed in Modde Pro (v.12.1), using ash-free conversion yield, aqueous TOC and $\mathrm{TN}$, residue solids $\mathrm{C} \%$ and $\mathrm{N} \%$ (and the corresponding aqueous TOC:TN and solid C:N ratios) as response factors. Fourdimensional response contour plots of ash-free yield versus temperature, salinity and catalyst type are presented in Fig. 4, and a summary of fit plot with further model detail is given in Fig. S2. In all cases, increasing temperatures resulted in greater biomass conversion to aqueous phase products; yields also were enhanced by the presence of salt in solution. This model supports 
(a) Cat. choice $\quad \operatorname{Temp}\left({ }^{\circ} \mathrm{C}\right)$

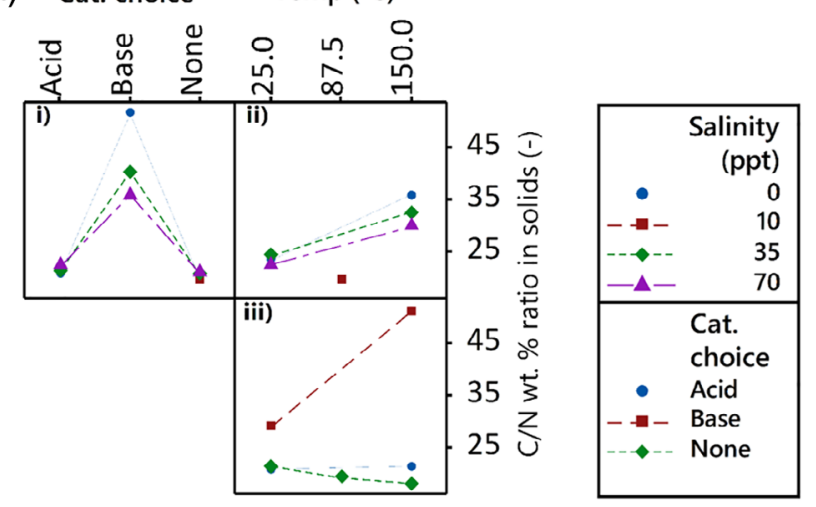

(b)

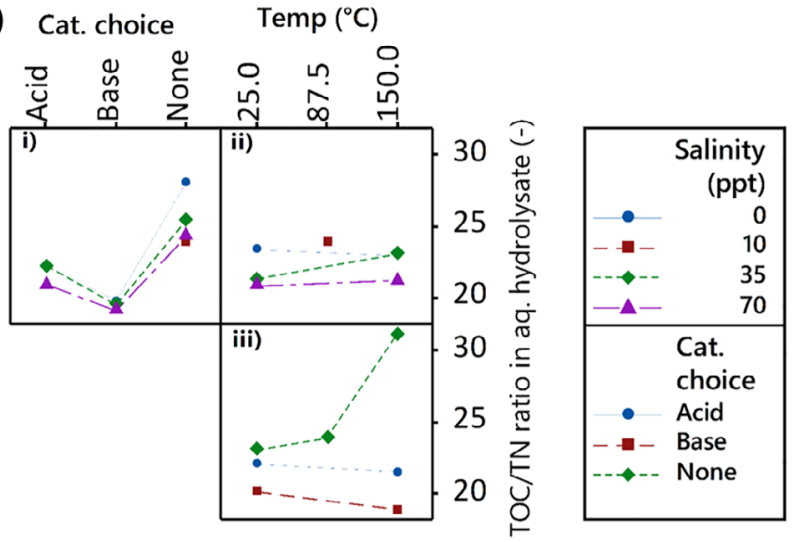

Figure 3. Interaction plots (produced in MINITAB V18.1) for the effect of salinity, catalyst (cat.), and temperature on, (a) the C:N wt\% mass ratio in the residual solids following fractionation. Subplots (a)-i: showing the relative interaction between catalyst choice and salinity (legend on right), (a)-ii: showing the relative interaction between temperature and salinity, and (a)-iii: showing the interaction between temperature and catalyst choice. For all subplots, axis on the right shows the average C:N wt\% ratio measured in the solid residues. (b) The TOC:TN mg L $\mathrm{L}^{-1}$ ratio in the aqueous hydrolysate following fractionation. Subplots (b)-i: showing the relative interaction between catalyst choice and salinity (legend on right), (b)-ii: showing the relative interaction between temperature and salinity, and (b)-iii showing the interaction between temperature and catalyst choice. For all subplots, axis on the right shows the average TOC:TN ratio measured in the aqueous hydrolysate. Colour version available online.

the findings of the interaction plots: base-catalysed processing is most sensitive to temperature variation, whereas acid-catalysed and catalyst-free processing is sensitive to both temperature and salinity. Similar $4 \mathrm{D}$ response plots were produced for TOC: $\mathrm{TN}$ ratio in the aqueous phase and $\mathrm{C}: \mathrm{N}$ ratio in the solids phase (see Fig. S3). These also suggest that reactions under basic conditions result in the highest $\mathrm{C}: \mathrm{N}$ ratio in the solids (resulting in low- $\mathrm{N}$ solids, beneficial for use of the solid as an HTL feedstock), and lowest TOC:TN ratio in the aqueous phase (which could be beneficial for use of the aqueous phase as a fertiliser).

\section{Analysis of soluble fraction}

The soluble fraction potentially can be used as a fermentation media, as such the saccharide composition of the hydrolysate was assessed by LC-MS (Fig. 5). Mannitol, fucose, glucose, rhamnose, mannose, galactose, fructose, maltose and xylose were quantified, based on the fucoidan carbohydrate structure of FS described by Bilan et al. and the microwave hydrolysis of brown seaweeds by Abeln et al., ${ }^{5,42}$ Xylose, mannose and galactose coeluted on the column used; however, use of the MS detection allowed separation of the pentose (xylose) and hexose (mannose, galactose), Mannose and galactose are presented as a combined, single MG fraction, and fructose/maltose/xylose were summed together as mixed sugars on Fig. 5, as their concentration was very low. Oligosaccharide concentration was quantified in comparison to a cellobiose standard for ease of comparison across all experimental conditions.

The various hydrolysis conditions show similar effect at liberating mannitol from the biomass structure, with mannitol found in all samples at concentrations ranging from 1.8 to $3.5 \mathrm{~g} \mathrm{~L}^{-1}$. Presence of salt was not seen to have a major impact on the concentration of mannitol recovered, with an average mannitol concentration of 2.7 and $2.4 \mathrm{~g} \mathrm{~L}^{-1}$ for $0 \mathrm{ppt}$ and $35 \mathrm{ppt}$ salinities, respectively. Similarly, the influence of temperature showed a relatively small difference, with lower temperature hydrolysis yielding slightly more mannitol than high temperature (2.7 and $2.3 \mathrm{~g} \mathrm{~L}^{-1}$ for 25 and $150^{\circ} \mathrm{C}$, respectively). Choice of catalyst showed an interesting trend, however, with the choice of no catalyst yielding the highest average mannitol concentration (3.0 $\left.\mathrm{g} \mathrm{L}^{-1}\right)$, compared to acid $\left(2.5 \mathrm{~g} \mathrm{~L}^{-1}\right)$ and base $\left(2.0 \mathrm{~g} \mathrm{~L}^{-1}\right)$ hydrolysis conditions. The decrease in mannitol concentration at elevated temperatures and under catalysed conditions (acid, base and/or salt) suggest that mannitol released into solution is undergoing further reaction to inhibitory products. Yamaguchi reports that mannitol dehydration to various degradation products progresses uncatalyzed in water at high temperature $(573 \mathrm{~K})$, or under $\mathrm{H}_{2} \mathrm{SO}_{4}$ conditions at $377 \mathrm{~K}^{43}$ Despite the clear indication of degradation of the easily soluble saccharides under acid/base conditions, the total saccharide yield for noncatalysed hydrolysis was typically much lower than either acid or base for all temperatures and salinities.

The quantity of oligosaccharides in solution was found to be higher in the samples hydrolysed in saltwater conditions, and the concentration of monosaccharides (fucose, glucose, MG and mixed sugars) unsurprisingly was highest for acid-treated samples, due to elevated hydrolysis of the more resistant biomass structures.

The mixed broth of mono-, di- and oligosaccharides, with variable salt content, would be unsuitable for the fermentation of a common yeast such as Saccharomyces cerevisiae. However, previous research has shown the capability of the highly tolerant yeast M. pulcherrima to catabolise a wide range of C5 and C6 monosaccharides and macroalgal oligosaccharides, as well as being extremely tolerant to the presence of inhibitors and elevated salt. $5,37,39,44$ To screen for the suitability of the hydrolysates for growing M. pulcherrima, the yeast was cultured on the hydrolysates, with no additional nutrients.

\section{Fermentation screen of $M$. pulcherrima using FS hydrolysates}

Fermentability was screened using 96-well plates, at a $300-\mu \mathrm{L}$ working volume scale (Fig. 6). The $\mathrm{OD}_{600}$ was recorded to approximate cell density. Measurements taken over the 5.5-day period demonstrated that $M$. pulcherrima was able to successfully metabolise FS hydrolysate produced using the full range of reaction conditions investigated. Final $\mathrm{OD}_{600}$ measurements were variable; however, a rapid onset of the exponential growth phase was observed for all conditions, demonstrated by a steep linear rise of $\mathrm{OD}_{600}$. In all cases the lag phase of the growth curve of the yeast 

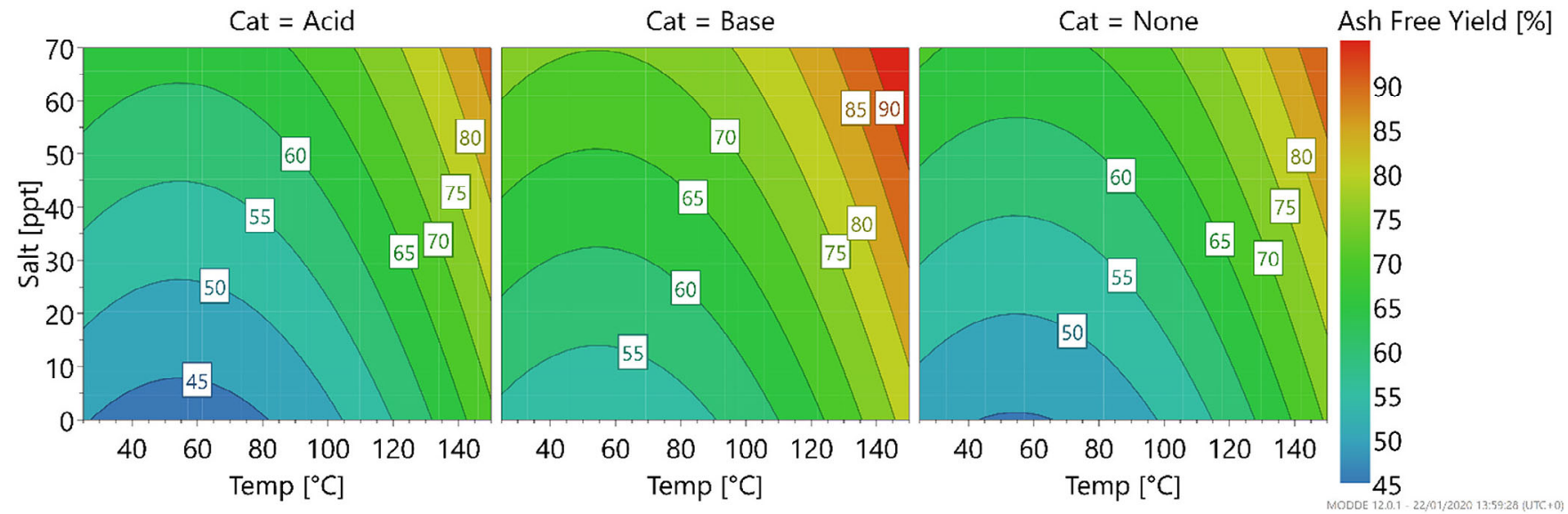

Figure 4. Four-dimensional response contour plot for multifactorial model assessing the effect of salinity $\left(0-70\right.$ ppt), temperature $\left(25-150^{\circ} \mathrm{C}\right)$ and catalyst choice (Acid, Base or None) on the predicted ash-free hydrolysis yield (wt\%). Model produced by partial least squares (PLS) regression correlation in ModDE PRO v12.0.1, summary of fit plot and further model details is included in Fig. S2. Colour version available online.

was extremely brief, typically $<2 \mathrm{~h}$, before the onset of the exponential growth phase.

The presence of high quantities of salt in the fermentation broth appeared to have had no impact on the final $\mathrm{OD}_{600}$ in all cases. Comparing the performance of $M$. pulcherrima in hydrolysates produced in freshwater (0 ppt), saltwater (35 ppt) and brine (70 ppt) [Fig. 6(g)] demonstrates that the effect of even a substantial salt content in the fermentation broth on $M$. pulcherrima growth is negligible. This suggests that saltwater processing of biomass will not negatively affect a downstream fermentation process based around a M. pulcherrima platform. Additionally, there is evidence that the presence of salt in the fermentation broth may assist with recovery of target bio-based molecules, such as 1,3-propanediol, 2,3-butanediol, acetoin and lactic acid. ${ }^{45}$

Acid pre-treatment is known to carry risk of producing toxic degradation products of both hexoses and pentoses. ${ }^{27,34,46}$ Nevertheless, growth of $M$. pulcherrima was unaffected in this case, due to its high inhibitor tolerance [Fig. 6(a) and (e)]. Favourably, base processing does not pose the same risk of producing toxic dehydration products from monomer sugars. However, due to the different mechanism of biomass digestion, although overall biomass conversion is higher, the yield of monosaccharides under $\mathrm{NaOH}$ treatment is significantly lower than with $\mathrm{H}_{2} \mathrm{SO}_{4}$. This was confirmed by LC-MS analysis of the hydrolysate, with individual sugars detected and quantified as described by Sluiter et al. (2011). ${ }^{41}$ Despite this, no significant difference in the performance of $M$. pulcherrima in $\mathrm{H}_{2} \mathrm{SO}_{4}$-treated versus $\mathrm{NaOH}$-treated biomass hydrolysates was observed across all temperature and salinity conditions [Fig. 6(i)].

\section{5-L scale-up}

From the small-scale screening study, it was concluded that baseassisted hydrolysis at high temperature was optimal, and from the 96-well fermentation screen it was concluded that the washing of

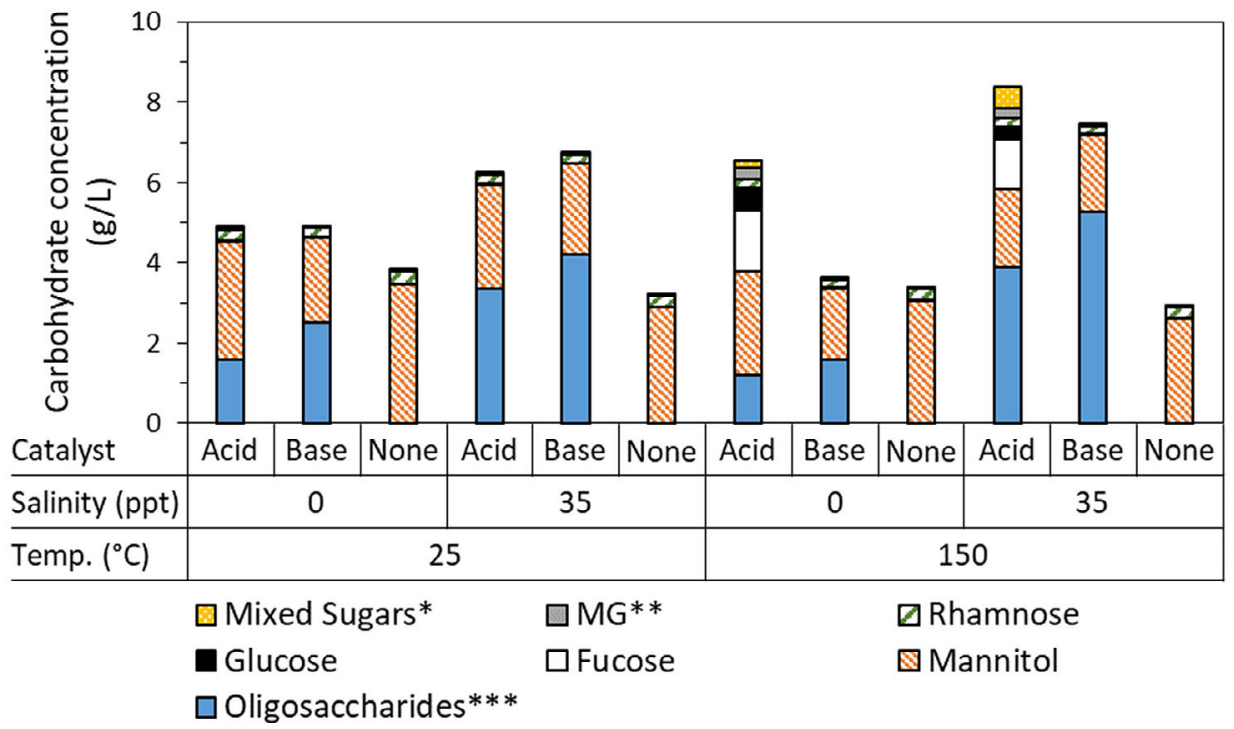

Figure 5. Concentrations of sugars in the hydrolysate determined by LC-MS for different experimental conditions. * Mixed Sugars, combined fructose, maltose, xylose saccharide fractions summed together. ${ }^{*} \mathrm{MG}$, combined mannose and galactose fractions that co-eluted together and thus were indistinguishable with the techniques used. ${ }^{* * *}$ Fucus serratus oligosaccharide was quantified in comparison to a cellobiose standard for ease of comparison across experimental conditions, and thus is an approximation. 

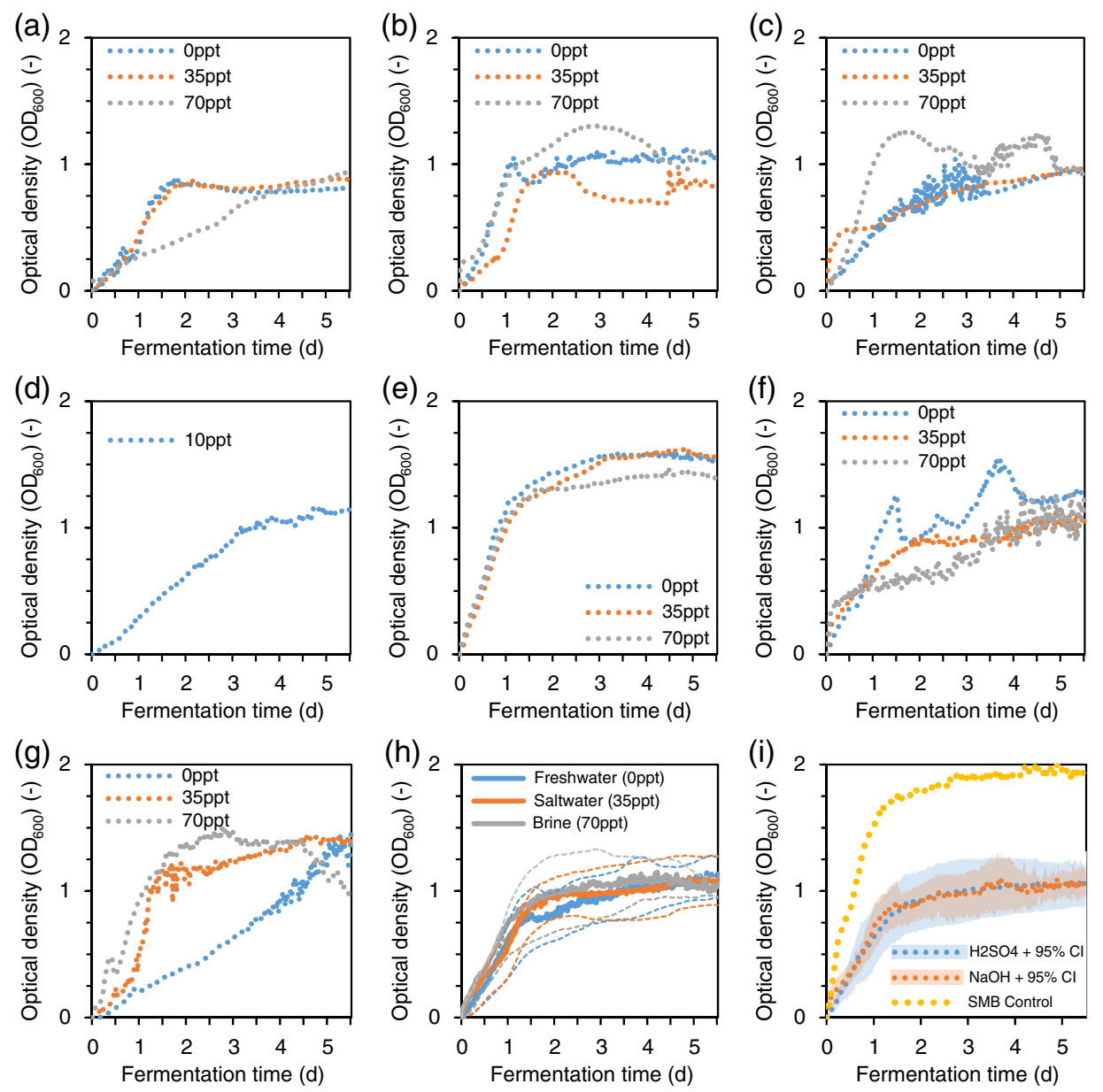

Figure 6. Average $\mathrm{OD}_{600}$ readings for Metschnikowia pulcherrima (NCYC 4331) grown on $F$. serratus hydrolysate produced by varied conditions in the fractionation screening experiments, for freshwater (0 ppt), saltwater ( $35 \mathrm{ppt}$ ) and heavy-brine (70 ppt): (a) $25^{\circ} \mathrm{C}, \mathrm{H}_{2} \mathrm{SO}_{4} ;$ (b) $25^{\circ} \mathrm{C}, \mathrm{NaOH}^{\prime}$ (c) $25^{\circ} \mathrm{C}$, no catalyst; (d) $87.5^{\circ} \mathrm{C}$, no catalyst; (e) $150^{\circ} \mathrm{C}, \mathrm{H}_{2} \mathrm{SO}_{4}$; (f) $150^{\circ} \mathrm{C}, \mathrm{NaOH}$; (g) $150^{\circ} \mathrm{C}$, no catalyst; (h) average $\mathrm{OD}_{600}$ by freshwater (0 ppt), saltwater ( $35 \mathrm{ppt}$ ), and brine (70 ppt) sample wells, for all catalyst choices and temperatures with $95 \% \mathrm{Cl}$ about each salinity as dotted lines; and (i) averaged $\mathrm{OD}_{600}$ by catalyst choice for all temperature and salinities, with shaded area representing a $95 \%$ confidence interval. $\mathrm{OD}_{600}$ scan was performed once every 30 min, plate was incubated and agitated between reads. Colour version available online.

harvested biomass to remove salt was not necessary to preserve the growth of $M$. pulcherrima. Fractionation therefore was repeated at a larger laboroatory scale, with the initial hydrolysis performed in a 5-L Parr stainless steel-jacketed stirred reactor. Scaling up presented an opportunity to produce a sufficient quantity of residual solids to evaluate the efficacy of performing HTL reactions on residual solids, as well as explore the conversion achieved at times $>20 \mathrm{~min}$. In order to retain sufficient residual solids after hydrolysis, a conversion of $\approx 50 \%$ to $55 \%$ during the first 20 min was targeted. A salinity of $\approx 8.5$ ppt was selected in order to model a large-scale system using brackish water at an estuary site, and using the 4D response contour plots generated previously (Fig. 4), a reaction temperature of $90^{\circ} \mathrm{C}$ was selected. In addition, mechanical agitation afforded an opportunity to increase solids loading, thus solid loading was increased to $\approx 13.5 \mathrm{wt} \%$.

Throughout the reaction, samples were drawn every $5 \mathrm{~min}$ after an initial 20-min period. Overall hydrolysis conversion yields ranged between $64 \%$ and $77 \%$, with a gradual increase in conversion observed over the 20- to 90-min reaction time [Fig. 7(a)]. Samples were neutralised using $\mathrm{HCl}$, and solids and aqueous phases separated by centrifugation. The solids were washed with DI water, and processed using HTL. The corresponding aqueous hydrolysate fractions were clarified and then used as fermentation media for M. pulcherrima in 100-mL Erlenmeyer (shake) flasks.

\section{Hydrothermal liquefaction of solid residues}

Solid extracts from the 5-L Parr reactor samples were processed using HTL to evaluate their suitability as a feedstock for bio-crude production. The HTL reactions were performed as described previously. ${ }^{8}$ Mass balances (the yields of bio-crude, solid char, aqueous phase organics and bio-gas) are presented in Fig. 7(b). For solids isolated at all stages of hydrolysis, higher bio-crude yields were obtained compared to performing HTL on unprocessed FS biomass. Additionally, the yield of solid bio-char was substantially lower for the first Parr reactor sample $(25 \mathrm{~min}$ ) relative to unprocessed FS biomass, although this increased with increasing hydrolysis time. As conversion of biomass increases with increasing hydrolysis time, as polysaccharides and oligosaccharides were solubilised, the solid residue became richer in insoluble material with a high ash content, leading to corresponding increases in the yield of HTL bio-char. The exception to this observation being the 80 min sample [Fig. 7(b)], which shows a decrease in the yield 


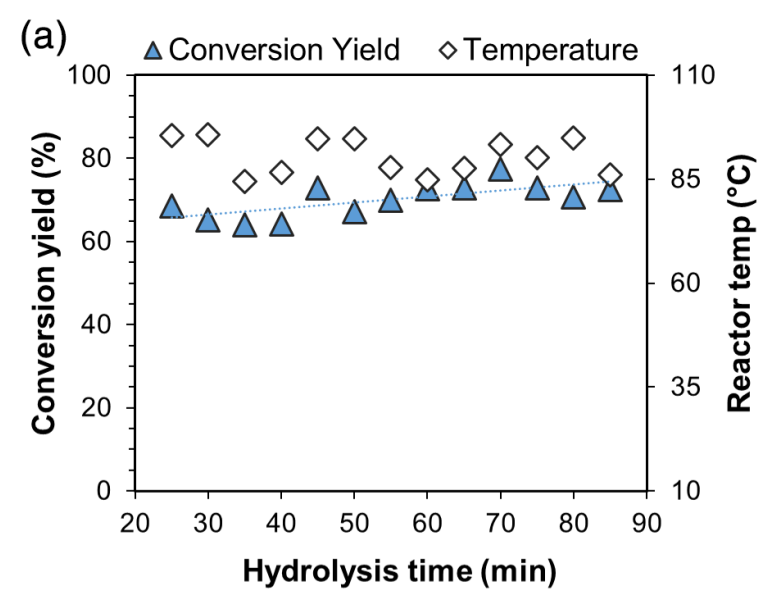

(b) $\square$ Bio-crude Solids $\square$ Aqueous residue $\square$ Gas

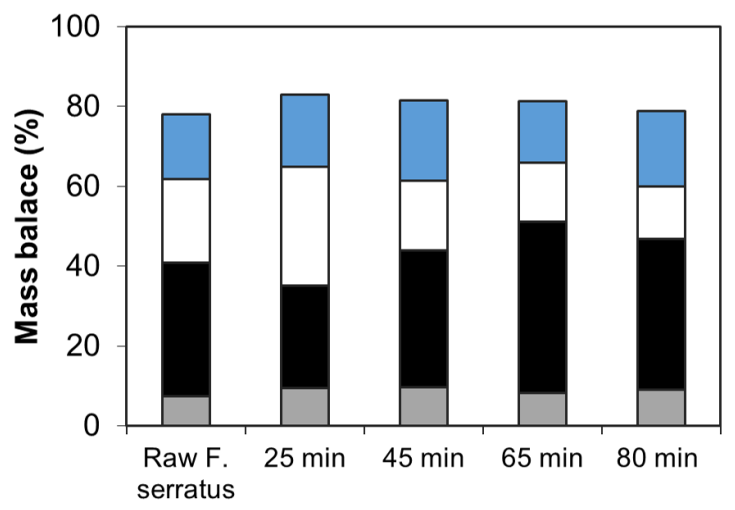

(c)

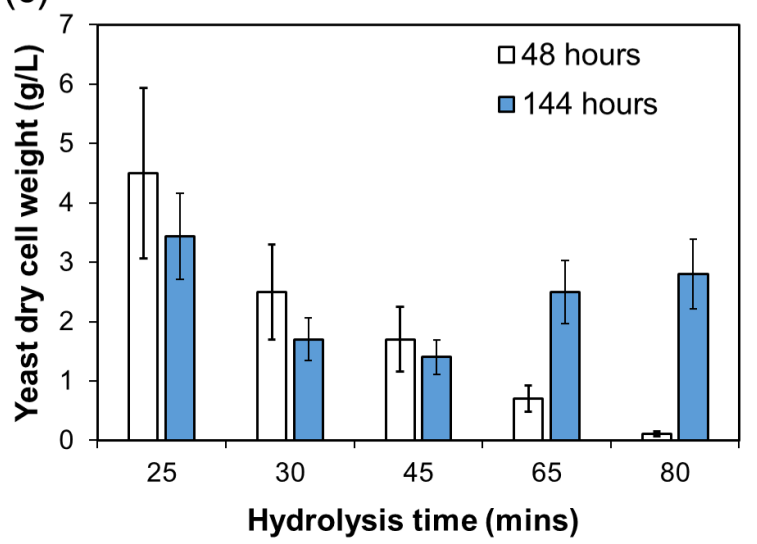

Figure 7. Conversion and subsequent valorisation of $\mathrm{NaOH}$-assisted $F$. serratus hydrolysis on a 5 - L scale, where (a) shows the overall conversion and temperature trend over the reaction time, (b) gives the mass balance for the resulting HTL reaction of the resulting solids after the same hydrolysis times, and (c) shows the dry cell weight achieved from culturing M. pulcherrima on the hydrolysates produced at 48 hand $144 \mathrm{~h}$. Colour version available online.

of bio-char and increase in the yield of bio-gas compared to the previous sample $(65 \mathrm{~min})$. Comparing the conversion yields for samples at 65 and $80 \mathrm{~min}$ [Fig. 7(a)], the $80 \mathrm{~min}$ sample sits slightly below the general observed trend with a conversion yield of $70.8 \%$, compared to $73.0 \%$ at $65 \mathrm{~min}$.
The overall mass closure ranged between $78.1 \%$ and $83.0 \%$ [Fig. 7(b)]. The $\approx 20 \%$ loss of material is due in part to light organics lost during the work-up of the bio-crude and thermal drying of the aqueous phase, as well as potentially oxygen removal as water into the aqueous phase. ${ }^{8,47}$ Overall these mass closures are similar to those observed by Raikova et al. in hydrothermal processing of the macroalgae $A$. nodosum, ${ }^{8}$ and by Anastasakis and Ross in hydrothermal processing of $L$. hyperborea, A. esculenta, L. digitata and L. saccharina. ${ }^{47}$

\section{Shake flask cultivation of $M$. pulcherrima}

Cultivation of $M$. pulcherrima using the $\mathrm{NaOH}$-treated hydrolysates produced at a $5-\mathrm{L}$ scale was carried out at the $100-\mathrm{mL}$ scale in shake flasks. The parameter $\mathrm{OD}_{600}$ was used to track growth of M. pulcherrima over $144 \mathrm{~h}$ total fermentation time (see Fig. S4, for full kinetic plots). The hydrolysates were fermented with no additional nutrients and the final dry cell weight was not strongly correlated with hydrolysis time, suggesting that a short fractionation reaction could be suitable for rapid $\mathrm{NaOH}$-assisted solvation of the fermentable carbohydrates from macroalgae [Fig. 7(c)].

Initial growth rates in the 0 to 2 day time-frame show a clear difference between hydrolysis times, with fermentation on shorter hydrolysis-time hydrolysates accumulating dry-cell mass significantly faster than longer hydrolysis-time samples. However, by the sixth day all differences in initial grow rates were normalised, with total accumulated dry-cell weights ranging between 1.4 and $3 \mathrm{~g} \mathrm{~L}^{-1}$ for all hydrolysis times, similar to previously reported fermentation on microwave-assisted hydrolysis of FS macroalgae. ${ }^{5}$ The pattern of differing growth rates and lag phases presumably is due to lower inhibitors being produced at the shorter reaction times, although the overall level of fermentable carbohydrate in the hydrolysis samples is approximately the same irrespective of hydrolysis time.

\section{CONCLUSIONS}

In conclusion, we have demonstrated that it is possible to perform both HTL and fermentation on the products of a saltwater- and $\mathrm{NaOH}$-treated macroalgae. $\mathrm{NaOH}$ as a hydrolysis catalyst offers advantages over dilute acid treatment in two ways: first, it selectively strips $\mathrm{N}$ from residue solids leaving a higher quality material for the HTL process; second, it presents a much simpler materials compatibility selection problem. The presence of salts in seawater when used as the reaction solvent enhanced the solids conversion yield of the hydrolysis reaction and had no demonstrable effect on the yeast $M$. pulcherrima when the salt-containing hydrolysate solution was used as a fermentation feedstock. Temperature was found to be the single highest influence on biomass solvation yields; however, the prospect of processing in seawater at lower temperatures offers some potential energy savings compared to freshwater processes. Residue solids from brackish and base treatment were advanced to HTL processing, where it was observed that $\mathrm{NaOH}$ pre-treatment of the biomass improved the biocrude yield, as well as decreasing the insoluble biochar product from the HTL reaction. This work provides a crucial missing step towards a true salt-based Marine Biorefinery (rather than a biorefinery simply based on marine biomass) by establishing the initial fractionation step, and crucially allowing the direct flow of biomass to HTL/Fermentation products by simply adjusting the temperature of the fractionation reaction. 


\section{ACKNOWLEDGEMENTS}

This work was partially supported by the Engineering and Physical Sciences Research Council (EP/L016354/1), through the Industrial Biotechnology Catalyst (Innovate UK, BBSRC, EPSRC) to support the translation, development and commercialisation of innovative Industrial Biotechnology processes (EP/N013522/1), the University of Exeter GCRF Global Research Translation Award: Sustainable Solutions to Food Security Challenges (EP/T015268/ 1); and the European Maritime and Fisheries Fund (EMFF) for support through grant ENG3418. The authors also would like to thank Rosie and Archie Allen for all their expert help in macroalgal harvesting.

\section{NOMENCLATURE}

$\begin{array}{ll}\text { DCW } & \text { Dry cell weight } \\ \text { FS } & \text { Fucus serratus } \\ \text { HTL } & \text { Hydrothermal liquefaction } \\ m_{\text {starting FS }} & \text { Initial starting mass of FS } \\ m_{\text {oven dry pellet }} & \text { Mass of oven dried biomass pellet } \\ \text { OD }_{600} & \text { Optical density of light absorbed at } 600 \mathrm{~nm} \\ & \text { wavelength } \\ \text { PLS } & \text { Partial least-squares regression } \\ \text { TGA } & \text { Thermogravimetric analysis } \\ \text { TN } & \text { Total nitrogen } \\ \text { TOC } & \text { Total organic carbon } \\ \text { MG } & \text { Mannose, and galactose combined sugars }\end{array}$

\section{REFERENCES}

1 Sudhakar K, Mamat R, Samykano M, Azmi WH, Ishak WFW and Yusaf T, An overview of marine macroalgae as bioresource. Renew Sustain Energy Rev 91:165-179 (2018). https://doi.org/10.1016/j.rser.2018. 03.100 .

2 van den Burg SWK, Dagevos H and Helmes RJK, Towards sustainable European seaweed value chains: a triple $\mathrm{P}$ perspective. ICES J Mar Sci (2019). https://doi.org/10.1093/icesjms/fsz183.

3 Ferdouse F, Holdt SL, Smith R, Murúa P and Yang Z, The global status of seaweed production, trade and utilization. FAO Globefish Res Program 124:120 (2018).

4 Silva A, Abreu H, Silva A and Cardoso S, Effect of oven-drying on the recovery of valuable compounds from Ulva rigida, Gracilaria sp. and Fucus vesiculosus. Mar Drugs 17:90 (2019). https://doi.org/ 10.3390/md17020090.

5 Abeln F, Fan J, Budarin VL, Briers H, Parsons S, Allen MJ et al., Lipid production through the single-step microwave hydrolysis of macroalgae using the oleaginous yeast Metschnikowia pulcherrima. Algal Res 38:101411 (2019). https://doi.org/10.1016/j.algal.2019.101411.

6 Chisti Y, Constraints to commercialization of algal fuels. J Biotechnol 167:201-214 (2013). https://doi.org/10.1016/j.jbiotec.2013.07.020.

7 Zhang W, Zhu J, Zhu X, Song M, Zhang T, Xin F et al., Expression of global regulator IrrE for improved succinate production under high salt stress by Escherichia coli. Bioresour Technol 254:151-156 (2018). https://doi.org/10.1016/j.biortech.2018.01.091.

8 Raikova S, Le CD, Beacham TA, Jenkins RW, Allen MJ and Chuck CJ, Towards a marine biorefinery through the hydrothermal liquefaction of macroalgae native to the United Kingdom. Biomass Bioenergy 107:244-253 (2017). https://doi.org/10.1016/j.biombioe.2017. 10.010.

9 Galbe $M$ and Wallberg O, Pretreatment for biorefineries: a review of common methods for efficient utilisation of lignocellulosic materials. Biotechnol Biofuels 12:1-26 (2019). https://doi.org/10.1186/ s13068-019-1634-1.

$10 \mathrm{Hu}$ Y, Feng S, Xu C and Bassi A, Production of low-nitrogen bio-crude oils from microalgae pre-treated with pre-cooled $\mathrm{NaOH} /$ urea solution. Fuel 206:300-306 (2017). https://doi.org/10.1016/j.fuel.2017. 06.021.
11 Raikova S, Knowles TDJ, Allen MJ and Chuck CJ, Co-liquefaction of macroalgae with common marine plastic pollutants. ACS Sustain Chem Eng 7: 6769-6781 (2019). https://doi.org/10.1021/acssuschemeng.8b06031.

12 Gollakota ARK, Kishore N and Gu S, A review on hydrothermal liquefaction of biomass. Renew Sustain Energ Rev 81:1378-1392 (2018). https://doi.org/10.1016/j.rser.2017.05.178.

13 Jung KA, Lim SR, Kim Y and Park JM, Potentials of macroalgae as feedstocks for biorefinery. Bioresour Technol 135:182-190 (2013). https:// doi.org/10.1016/j.biortech.2012.10.025.

14 Lee JY and Kim YS, Optimization the process variables for the fractionation of Saccharina japonica to enhance glucan content. J Ind Eng Chem 19:938-943 (2013). https://doi.org/10.1016/J.JIEC.2012. 11.011 .

15 Sterner $\mathrm{M}$ and Edlund $\mathrm{U}$, Multicomponent fractionation of Saccharina latissima brown algae using chelating salt solutions. $J$ Appl Phycol 28:2561-2574 (2016). https://doi.org/10.1007/s10811-015-0785-0.

16 Herrero $M$ and Ibáñez $E$, Green processes and sustainability: an overview on the extraction of high added-value products from seaweeds and microalgae. J Supercrit Fluids 96:211-216 (2015). https://doi.org/ 10.1016/j.supflu.2014.09.006.

17 Laurens LML, Nagle N, Davis R, Sweeney N, Van Wychen S, Lowell A et al., Acid-catalyzed algal biomass pretreatment for integrated lipid and carbohydrate-based biofuels production. Green Chem 17: 1145-1158 (2015). https://doi.org/10.1039/C4GC01612B.

18 Tamayo Tenorio A, Kyriakopoulou KE, Suarez-Garcia E, van den Berg C and van der Goot AJ, Understanding differences in protein fractionation from conventional crops, and herbaceous and aquatic biomass - consequences for industrial use. Trends Food Sci Technol 71: 235-245 (2018). https://doi.org/10.1016/j.tifs.2017.11.010.

19 Vuai SAH and Mpatani F, Optimization of agar extraction from local seaweed species, Gracilaria salicornia in Tanzania. Phycol Res 67: 261-266 (2019). https://doi.org/10.1111/pre.12380.

20 Neveux N, Yuen AKL, Jazrawi C, He Y, Magnusson M, Haynes BS et al., Pre- and post-harvest treatment of macroalgae to improve the quality of feedstock for hydrothermal liquefaction. Algal Res 6:22-31 (2014). https://doi.org/10.1016/J.ALGAL.2014.08.008.

21 Xu D, Lin G, Guo S, Wang S, Guo Y and Jing Z, Catalytic hydrothermal liquefaction of algae and upgrading of biocrude: a critical review. Renew Sustain Energ Rev 97:103-118 (2018). https://doi.org/10. 1016/j.rser.2018.08.042.

22 Wagner JL, Perin J, Coelho RS, Ting VP, Chuck CJ and Teixeira FT, Hydrothermal conversion of lipid-extracted microalgae hydrolysate in the presence of isopropanol and steel furnace residues. Waste Biomass Valorization 9:1867-1879 (2018). https://doi.org/10.1007/s12649017-9944-7.

23 Galadima A and Muraza O, Hydrothermal liquefaction of algae and biooil upgrading into liquid fuels: role of heterogeneous catalysts. Renew Sustain Energ Rev 81:1037-1048 (2018). https://doi.org/10. 1016/j.rser.2017.07.034.

24 Htet AN, Noguchi M, Ninomiya K, Tsuge Y, Kuroda K, Kajita S et al., Application of microalgae hydrolysate as a fermentation medium for microbial production of 2-pyrone 4,6-dicarboxylic acid. J Biosci Bioeng 125:717-722 (2018). https://doi.org/10.1016/j.jbiosc.2017. 12.026 .

25 Kumar G, Sivagurunathan P, Anburajan P, Pugazhendhi A, Saratale GD, Choi C-S et al., Continuous biogenic hydrogen production from dilute acid pretreated algal hydrolysate using hybrid immobilized mixed consortia. Int J Hydrogen Energ 43:11452-11459 (2018). https://doi.org/10.1016/J.IJHYDENE.2017.06.050.

26 Gnanasekaran R, Dhandapani B and lyyappan J, Improved itaconic acid production by aspergillus niveus using blended algal biomass hydrolysate and glycerol as substrates. Bioresour Technol 283: 297-302 (2019). https://doi.org/10.1016/J.BIORTECH.2019.03.107.

27 Fang C, Thomsen MH, Frankær CG, Bastidas-Oyanedel JR, Brudecki GP and Schmidt JE, Factors affecting seawater-based pretreatment of lignocellulosic date palm residues. Bioresour Technol 245:540-548 (2017). https://doi.org/10.1016/j.biortech.2017.08.184.

$28 \mathrm{Kim}$ Y, Yu A, Han M, Choi GW and Chung B, Ethanosolv pretreatment of barley straw with iron(III) chloride for enzymatic saccharification. J Chem Technol Biotechnol 85:1494-1498 (2010). https://doi.org/10. 1002/jctb.2455.

29 Aslanzadeh S, Ishola MM, Richards T and Taherzadeh MJ, Cellulosic biomass processing \& biorefinery road map, in Biorefineries - Integrated Biochemical Processes for Liquid Biofuels, ed. by Qureshi N, Hodge DB and Vertès AA. Oxford, UK, Elsevier, pp. 3-36 (2014). 
30 Tan J, Abdel-Rahman MA and Sonomoto K, Biorefinery-based lactic acid fermentation: microbial production of pure monomer product, in Synthesis, Structure and Properties of Poly(Lactic Acid) Advances in Polymer Science, Vol. 279, ed. by Lorenzo ML and Androsch R. Springer International, Cham, pp. 27-66 (2018). https://doi.org/10. 1007/12_2016_11.

31 Karp SG, Igashiyama AH, Siqueira PF, Carvalho JC, Vandenberghe LPS, Thomaz-Soccol V et al., Application of the biorefinery concept to produce I-lactic acid from the soybean vinasse at laboratory and pilot scale. Bioresour Technol 102:1765-1772 (2011). https://doi. org/10.1016/j.biortech.2010.08.102.

32 Bedő $S$, Antal B, Rozbach M, Fehér A and Fehér C, Optimised fractionation of wheat bran for arabinose biopurification and xylitol fermentation by Ogataea zsoltii within a biorefinery process. Ind Crops Prod 139:111504 (2019). https://doi.org/10.1016/j.indcrop. 2019.111504

33 Kostas ET, White DA and Cook DJ, Bioethanol production from UK seaweeds: investigating variable pre-treatment and enzyme hydrolysis parameters. Bioenergy Res (2019). https://doi.org/10.1007/s12155019-10054-1.

34 Saratale GD, Al-Muhtaseb AH, Chang J-S, Kumar G, Nemestóthy N, Xia $A$ et al., A review on the biomass pretreatment and inhibitor removal methods as key-steps towards efficient macroalgae-based biohydrogen production. Bioresour Technol 244:1341-1348 (2017). https://doi.org/10.1016/j.biortech.2017.05.172.

35 Chandel AK, da Silva SS and Singh OV, Detoxification of lignocellulose hydrolysates: biochemical and metabolic engineering toward White biotechnology. Bioenergy Res 6:388-401 (2013). https://doi.org/10. 1007/s12155-012-9241-z.

36 Santamauro F, Whiffin FM, Scott RJ and Chuck CJ, Low-cost lipid production by an oleaginous yeast cultured in non-sterile conditions using model waste resources. Biotechnol Biofuels 7:1-11 (2014). https://doi.org/10.1186/1754-6834-7-34.

37 Fan J, Santomauro F, Budarin VL, Whiffin F, Abeln F, Chantasuban $\mathrm{T}$ et al., The additive free microwave hydrolysis of lignocellulosic biomass for fermentation to high value products. J Clean Prod 198:776-784 (2018). https://doi.org/10.1016/j. jclepro.2018.07.088.

38 Remón J, Santomauro F, Chuck CJ, Matharu AS and Clark JH, Production of fermentable species by microwave-assisted hydrothermal treatment of biomass carbohydrates: reactivity and fermentability assessments. Green Chem 20:4507-4520 (2018). https://doi.org/10. 1039/C8GC02182A.

39 Santomauro F, Fan J, Budarin VL, Parsons S, Clark J, Miller T, Chuck CJ, Microbial oil produced from the fermentation of microwavedepolymerised rapeseed meal. Bioresour Technol Rep 4:159-165 (2018). https://doi.org/10.1016/j.biteb.2018.10.008.

40 Piccini M, Raikova S, Allen MJ and Chuck CJ, A synergistic use of microalgae and macroalgae for heavy metal bioremediation and bioenergy production through hydrothermal liquefaction. Sustain Energ Fuels 3:292-301 (2019). https://doi.org/10.1039/C8SE00408K.

41 Sluiter A, Hames B, Ruiz RO, Scarlata C, Sluiter J and Templeton D, Determination of structural carbohydrates and lignin in biomass. Technical Report NREL/TP-510-42618, National Renewable Energy Laboratory, Golden, CO, (2008)

42 Bilan MI, Grachev AA, Shashkov AS, Nifantiev NE and Usov Al, Structure of a fucoidan from the brown seaweed Fucus serratus L. Carbohydr Res 341:238-245 (2006). https://doi.org/10.1016/j.carres.2005.11.009.

43 Yamaguchi A, Sato O, Mimura N and Shirai M, Intramolecular dehydration of mannitol in high-temperature liquid water without acid catalysts. RSC Adv 4:45575-45578 (2014). https://doi.org/10.1039/ C4RA09198A.

44 Zhou L, Santomauro F, Fan J, Macquarrie D, Clark J, Chuck CJ et al., Fast microwave-assisted acidolysis: a new biorefinery approach for the zero-waste utilisation of lignocellulosic biomass to produce high quality lignin and fermentable saccharides. Faraday Discuss 202: 351-370 (2017). https://doi.org/10.1039/C7FD00102A.

45 Dai JY, Sun YQ and Xiu ZL, Separation of bio-based chemicals from fermentation broths by salting-out extraction. Eng Life Sci 14:108-117 (2014). https://doi.org/10.1002/elsc.201200210.

46 van der Pol E, Bakker R, van Zeeland A, Sanchez Garcia D, Punt A and Eggink $G$, Analysis of by-product formation and sugar monomerization in sugarcane bagasse pretreated at pilot plant scale: differences between autohydrolysis, alkaline and acid pretreatment. Bioresour Technol 181:114-123 (2015). https://doi.org/10.1016/j.biortech. 2015.01.033.

47 Anastasakis $\mathrm{K}$ and Ross $\mathrm{AB}$, Hydrothermal liquefaction of the brown macro-alga Laminaria saccharina: effect of reaction conditions on product distribution and composition. Bioresour Technol 102: 4876-4883 (2011). https://doi.org/10.1016/j.biortech.2011.01.031. 